\title{
MONIKA LISOWSKA
}

Universidad de Varsovia

\section{LA EXPRESIÓN VERBAL DE LAS EMOCIONES NEGATIVAS: EL CASO DEL INSULTO}

\begin{abstract}
A b stract. Lisowska Monika, La expresión verbal de las emociones negativas: el caso del insulto. [The Verbal Expression of Negative Emotions: The Case of Insult], Studia Romanica Posnaniensia, Adam Mickiewicz University Press, Poznań, vol. XXXVII/2: 2010, pp. 3-13. ISBN 978-83-232-2189-0. ISSN 01372475. DOI 10.2478/v10123-010-0010-6.
\end{abstract}

An insult is one of the cases of verbal aggression and undoubtedly it is an everyday life phenomenon. Insulting is a display of direct aggression which arises from anger and aims at the effect on the recipient's mind. The act of abuse on the other hand, is conditioned by multiple factors. Its success depends, for example, on the knowledge of culture to which the recipient of an insult belongs. Despite the fact that an insult is a cultural phenomenon, i.e. dependent on a particular culture, the mechanism of abuse itself is identical in the entire world. Generally, way it is possible to determine a list of universal human disabilities which are subject to insults as well as a universal list of topic areas of insulting expressions.

\section{EXPRESIÓN EMOCIONAL: FUNDAMENTOS TEÓRICOS ${ }^{1}$}

\subsection{EXPRESIÓN EMOCIONAL VS. DESCRIPCIÓN DE LA EXPERIENCIA EMOCIONAL}

La expresión de emociones mediante los recursos lingüísticos es un fenómeno muy frecuente en la comunicación humana. Como ya observó Charles Bally, el emisor habitualmente tiñe sus enunciados con elementos afectivos (Bally, 1966, p. 52).

Es verdad que la manifestación de las emociones ocurre tan sólo en parte pequeña en el plano lingüístico, y el lenguaje no es el código más importante que desempeña esta función (Grabias, 1981, p. 17). Tenemos que ser conscientes de que alrededor del 55\% de la información la aportan las experiencias corporales, como gestos convencionales, mímica, aspecto físico y comportamiento, denominados comúnmente "lenguaje de cuerpo"; un $37 \%$ de la información es proporcionado por la voz, el tono y la acentuación; y tan sólo un 8\% por la palabra (Nowakowska-Kempna, 2000, p. 75).

${ }^{1}$ El punto de partida para el presente trabajo lo constituyen algunas de las reflexiones de nuestra tesis doctoral entitulada La expresión de las emociones en el chat hispano mediante los recursos lingüisticos, presentada en el Departamento de Filologías de la Universidad de Łódź en el mayo de 2007. 
Sin embargo, a pesar de tan poca participación del lenguaje en la transmisión de la información sobre la experiencia emocional, hay que reconocer que esta participación existe, y que la palabra, aunque en general representa una idea-ser, es a la vez capaz de soportar una emoción: «Es una verdad que no hay palabra que no sea capaz de expresar en un caso determinado alguna afectividad. No hay palabra alguna que sea puramente ontológica y que no sea potencialmente axiológica también» (García de Diego, 1966, p. 17).

Los seres humanos podemos transmitir verbalmente nuestra experiencia emocional de dos maneras: comunicar - o sea, describir - o expresarla. Según apunta Kövecses (2002, p. 2), es necesario hacer distinción entre las palabras que describen emociones y las que las expresan.

Así, la descripción (comunicación) de la experiencia emocional supone hablar de lo que se siente: (i) nombrar sentimientos (tristeza, amor ${ }^{2}$ ), (ii) nombrar síntomas de los sentimientos (ponerse colorado), (iii) nombrar actividades y comportamientos relacionados con las emociones (bailar de alegría), (iv) nombrar experiencias relacionadas con una emoción dada (ponérsele a alguien los pelos de punta) (NowakowskaKempna, 1995, p. 17). En general, en la descripción de la experiencia emocional ${ }^{3}$ se utilizan sustantivos que nombran las emociones, sintagmas verbales y unidades fraseológicas que explican de manera descriptiva de qué emoción se trata (Nowakowska-Kempna, 2000, p. 75).

Mientras tanto, la expresión emocional consiste en transmitir "clandestinamente" una información que va adjunta al enunciado y que el oyente tiene que descodificar basándose en su competencia lingüístico-pragmática. La expresión emocional puede darse en diferentes niveles de la lengua ${ }^{4}$, informando en qué estado emocional se encuentra el individuo "aquí y ahora". Es la forma de presentar la experiencia emocional más frecuente que la relacionada con la comunicación de emociones. Eso se debe a que el hombre habitualmente se niega a indicar formalmente a sí mismo como al experimentador de un estado psíquico dado (Szumska, 2000, p. 200).

De estas dos maneras de transmitir verbalmente emociones es la expresión emocional en la que nos vamos a enfocar en el presente artículo, presentando uno de los casos de ésta: el insulto. En nuestro trabajo partimos de la convivcción de que insultos funcionan como signos lingüísticos expresivos.

\footnotetext{
${ }^{2}$ Los ejemplos son nuestros.

${ }^{3}$ Como observa Grzegorczykowa (1978, p. 121), algunas emociones básicas, como el miedo, la vergüenza, el amor y el odio, en el lenguaje pueden ser sólo comunicadas, no expresadas.

${ }^{4}$ Por ejemplo, fonológico, morfológico, léxico, oracional, sintáctico (Volek, 1987, pp. 15-24).

5 Expresar emociones sólo puede ser ,aquí y ahora”, el comunicar emociones no tiene limitaciones de este tipo.

${ }^{6}$ Esta afirmación se refiere, a nuestro juicio, a las situaciones en que el sujeto informa sobre sus estados psíquicos actuales.
} 


\subsection{SIGNO LINGÜÍSTICO EXPRESIVO}

Según apunta Volek (1987), el fenómeno central de la verbal expresión emocional lo constituyen aquellos medios lingüísticos que sirven para la expresión $\operatorname{directa}^{7}$ de $^{2}$ la actitud emocional actual del hablante (y no para la expresión de "ideas de emociones"). Y son ellos los que se establecen como signos especiales que expresan emociones $^{8}$ en una lengua dada.

Se trata, evidentemente, de los así llamados signos lingüísticos expresivos ${ }^{9}$. En las condiciones naturales, el signo expresivo es semiótico y funciona conforme al principio de contigüidad, pero la naturaleza de los signos lingüísticos consiste en que la relación entre el significante y el significado se basa en la arbitrariedad ${ }^{10}$.

El signo lingüístico expresivo, a parte de los componentes intelectuales, lleva también incluido un componente emocional de carácter indicativo (Grabias, 1978, p. 109). Según explica Volek, «The relationship of the emotive sign to its object is different from that of a notional sign to its denotatum» (Volek, 1987, p. 25). Eso se debe a que los componentes intelectuales se basan en nociones o conceptos, y los emocionales en el reflejo de la experiencia emocional que no queda comprendida en el significado nocional del signo lingüístico (Volek, 1987, p. 26).

Existen dos tipos de signos lingüísticos independientes: los signos nominativos y los predicativos ${ }^{11}$. La emocionalidad, entendida como la expresada actitud del emisor hacia la realidad comunicada, es el rasgo constante de los enunciados con carácter emotivo, o sea, de los signos predicativos expresivos. Esto quiere decir, que los enunciados tales como por ejemplo: “iQué estupido es!” o "¡Me cago en la leche!” fuera del contexto no dejan de ser entendidos como comunicados con matiz emocional.

En cambio, si se trata de la emocionalidad de los signos nominativos, en la estructura de estos signos, además de los componentes semánticos, existe también un componente pragmático de la evaluación del denotado nombrado por la palabra. La diferencia entre la expresividad emocional de los signos predicativos y la de los signos nominativos reside en que, en el caso de estos últimos, dicha expresividad es un rasgo potencial que se realiza en ellos cuando estos signos aparecen en un enunciado ${ }^{12}$

7 "Expresión directa" en Volek (1987) significa "expresión inmediata", así como "expresar emociones" para esta autora equivale a "mostrar emociones directamente".

${ }^{8}$ Special signs expressing emotions (Volek, 1987, p. 12).

9 Término adoptado según Grabias (1981).

${ }^{10} \mathrm{O}$ sea, que «Ce qui est arbitraire c'est que tel signe, et non tel autre, soit appliqué à tel élément de la réalité, et non à tel autre» (Beneveniste, 1966, p. 52).

${ }_{11}$ Traducimos la terminología utilizada por Grabias (1981), quien por signo nominativo entiende toda palabra unidad de diccionario y por signo predicativo - el enunciado.

12 Por supuesto, hay que mencionar que existe un grupo de signos nominativos que poseen un matiz afectivo fijo, independientemente del contexto o de la situación (Spagińska-Pruszak, 1994, p. 10), p.ej.: "bastardo". En las palabras de este tipo la emocionalidad es el componente semántico del lexema, así que ellas tienen una relación fija con la expresión de los estados emocionales. No 
(Grabias, 1981, p. 37). Ello quiere decir que la expresividad de los signos nominativos depende, habitualmente, del contexto ampliamente endtendido ${ }^{13}$.

El grupo especial de los signos nominativos expresivos que nos ocupa en el presente artículo son las palabras insultantes. A las palabras de esta categoría se les atribuye una gran carga emocional, puesto que suelen ser asociadas con el comportamiento lingüístico sumamente descortés, o sea, con la agresión verbal.

\section{AGRESIÓN VERBAL: RASGOS Y TIPOS}

La agresión es una de las disposiciones instintivas del hombre. Habitualmente es asociadada con la expresión espontánea y no controlada de las emociones negativas. Se le atribuyen los siguientes rasgos: actividad, intención destructiva, voluntad de dominación, falta de sensibilidad.

Sin duda, la agresión es un instinto innato, pero las maneras de expresarla se aprenden viviendo en la sociedad. Así, cada acto agresivo debe ser estudiado en el contexto social y cultural-normativo en que actúa el agresor, su víctima y/o el oyenteobservador ${ }^{14}$. Cabe destacar que hay dos tipos de agresión: (a) la agresión originada por el enfado ${ }^{15} \mathrm{y}$ (b) la agresión instrumental que se produce con la intención de conseguir algo a cambio (Peisert, 2004, p. 24).

La agresión verbal, tanto la colérica como la instrumental, se enmarca dentro de lo que en psicología se llama la agresión psíquica. Se trata de una actividad verbal cuyo objetivo es destruir o herir el ego del contrario, y, según los estudios de la cortesía, deteriorar la imagen pública positiva de éste.

Las estrategias de ataques verbales pueden dividirse en varios grupos, según su forma. Peisert (2004, p. 31) propone la división siguiente:

1) agresión directa, que expresa explícitamente contenidos negativos orientados hacia el destinatario de dos maneras:

a) mediante el uso del léxico insultante ${ }^{16}$,

b) mediante el uso del léxico neutral ${ }^{17}$,

2) agresión ejecutada a espaldas del destinatario, por ejemplo mediante chismes $\mathrm{u}$ otras actividades verbales que deshonran a la víctima,

obstante, es en los enunciados donde se actualiza el pleno valor de dichos lexemas, ya que los enunciados presentan mejor las intenciones del emisor.

13 Sobre todo el contexto físico (emisor, destinatario, situación espacio-temporal), empírico (información pragmática, intención) y cultural (tradición cultural).

${ }^{14}$ Para que un acto sea considerado como agresivo cuenta no sólo la intención del emisor sino también la impresión de la víctima potencial y la opinión del oyente-observador, en algunos casos también la opinión del juez (Peisert, 2004, p. 23).

15 Agresión colérica.

16 Comúnmente percibido como tal.

${ }^{17}$ Que, en principio, carece del valor insultante, pero según el contexto en que aparezca puede adquirirlo. 
3) agresión implicada, es decir, la que no se puede deducir del contenido literal del mensaje sino que se desprende del análisis del contexto y de la situación que acompaña al acto de la comunicación lingüística.

La agresión verbal originada por el enfado es un caso obvio de la expresión emocional que se manifiesta a través de las unidades de la lengua. Nos referimos a un acto verbal más o menos agresivo ${ }^{18}$, durante el que el emisor expresa explícita y directamente contenidos negativos orientados hacia el contrario. Es el acto de insultar.

\section{INSULTOS}

\subsection{EL ACTO DE INSULTAR}

De toda una gama de elementos que pueden ser utilizados en el acto de la agresión verbal, son los insultos que, a nuestro juicio, merecen una atención especial. Según hemos indicado supra, lo que ocurre durante el acto de insultar es la expresión directa y explícita de contenidos negativos orientados hacia el contrario. Dicha expresión es la reacción del emisor a un estímulo valorado por él como negativo ${ }^{19}$.

En cuanto a lo qué debe considerarse insulto y qué no, merece presentar las palabras de Colín Rodea (2005, p. 15): "El tema del insulto debe observarse desde dos líneas: el grupo de las ideas difusas (todo puede ser insulto) y el de los elementos esenciales (el insulto se materializa en las palabras)". Partiendo de esta observación, Colín Rodea formula la siguiente definición del insulto:

[...] el insulto es una acción verbal y/o no verbal, sancionada como ofensiva, cuyas unidades léxicas pueden o no representar en sí mismas una carga insultante al evocar conceptos socialmente convenidos para ello; entendido así: todo lo que tenga un efecto cognoscitivo o contextual que pueda parafrasearse y/o reconocerse como descalificante es un insulto (Colín Rodea 2005, p. 32).

Insultar es una actividad compleja que comprende elementos del nivel verbal, gestual ${ }^{20}$ y el de movimientos faciales (Mikołajczyk, 2007, p. 191). Cabe indicar que los elementos de este último nivel no se pueden separar del acto de insultar: un insulto verbal o gestual siempre va acompañado por una determinada expresión facial.

Si nos limitamos al aspecto verbal ${ }^{21}$, insultar es un acto de habla, o sea, el insulto pertenece al grupo de esas palabras que "hacen cosas", como la promesa o la orden.

${ }^{18}$ El grado de la agresividad depende, por supuesto, de la capacidad del sujeto de controlar sus emociones.

${ }^{19} \mathrm{La}$ evaluación intelectual y la actitud emocional son componentes constitutivos de la función expresiva.

${ }^{20}$ Se puede insultar sin el uso de palabras, por ejemplo, tan sólo mediante gestos - recordemos el clásico insulto con el dedo mayor - aunque hay quienes consideran que el insulto por antonomasia es sobre todo verbal.

21 Es decir, a los elementos esenciales, según ya mencionada división propuesta por Colín Rodea. 
Según señala Grzegorczykowa (1991, pp. 199-200), la esencia del insulto reside en decir palabras que tienen un matiz emocional negativo. Se trata de un comportamiento lingüístico caracterizado por el uso del léxico expresivo, capaz de expresar la actitud negativa hacia el destinatario en el momento de realizar la actividad lingüística. La intención del uso de tal léxico - léxico insultante - es siempre la misma: humillar, rebajar la dignidad del destinatario.

Desde luego no todos los enunciados que contienen palabras ofensivas pueden ser considerados como actos de insultar. Todavía deben cumplirse otras dos condiciones: (a) el enunciado del emisor $\mathrm{X}$ debe ser dirigido hacia el receptor $\mathrm{Y}$, o debe, al menos, ser pronunciado en público (Grzegorczykowa, 1991), (b) el receptor del mensaje debe sentirse ofendido ${ }^{22}$ (Pisarkowa, 1978, p. 117). Conviene subrayar que este acto de la agresión no exige necesariamente la participación directa del receptor del ataque. El acto de insultar puede tener lugar en la presencia de una persona tercera y el objeto del ataque puede estar ausente. Lo importante es la intención de ofender ${ }^{23}$ y los medios que se utilicen con este fin.

Insultar es una de las maneras de expresar verbalmente el estado emocional actualmente vivido. Dado el objetivo de carácter negativo que tiene la acción de insultar, se trata, obviamente, de la expresión de emociones negativas, como la ira, el enojo o el enfado. Las maneras de insultar verbalmente varían de una cultura a otra. Cada lengua no sólo cuenta con su propio caudal de voces insultantes, sino también posee un grupo fijo de las expresiones que las refuerzan. Este hecho está estrechamente relacionado con la cultura. En este aspecto es importante recordar que:

Los insultos son termómetros culturales muy precisos. Lo que se reprocha en el fondo es ni más ni menos lo que la cultura rechaza y lo que las normas sociales desaprueban. [...] Es innegable el componente cultural, espacial y social de los insultos, pues lo que es denigrante y ofensivo en una cultura, lugar o región concretos, en un grupo social preciso, no tiene por qué serlo en otro. Es imposible separar los insultos de la cultura que los crea y utiliza ( $\mathrm{Da}$ Riva, 2007, p. 28).

Aunque el valor insultante de una palabra o un gesto está estrechamente relacionado con la cultura y la sociedad que los utiliza, el mecanismo en que se apoya la acción de insultar es igual para toda la raza humana ${ }^{24}$ : dar donde más duele. Lo más habitual en el acto de insultar es referirse a los - más o menos evidentes - defectos

${ }^{22}$ No comparte esta opinión Grzegorczykowa que cree que esta condición no es necesaria: si el destinatario no se siente ofendido, entonces el acto es incompleto, pero no deja de ser el acto de insultar (Grzegorczykowa, 1991, p. 200).

23 Según Grzegorczykowa (1991), la falta de intención de insultar por parte del emisor - cosa que no se puede comprobar - no puede ser considerada como base para anular el insulto, aunque, sin duda, contribuye a la imperfectividad de aquél.

${ }^{24}$ El lenguaje ofensivo ha existido en todos los tiempos y en todas las culturas de ahí que pueda ser considerado como el fenómeno universal intercultural, usado de la misma manera por todas las partes del mundo (Van Oudenhoven et al., 2008, p. 176). 
del destinatario del ataque verbal ${ }^{25}$. Aquí, cabe subrayar que insultando el emisor no pretende enunciar la verdad objetiva, no es éste su fin. Lo que cuenta es comportarse verbalemente de la manera que el destinatario pueda sentirse ofendido, humillado por las palabras hirientes dirigidas hacia él. De ahí que una de las estrategias frecuentes en la acción de insultar sea soltar cualquier palabra insultante que pueda logar su fin, sin que su contenido semántico refleje el verdadero estado de cosas. O sea, en otras palabras, no siempre se trata de referirse a los defectos reales, en muchos casos estos defectos se inventan, el emisor más bien sugiere al destinatario la posesión de éstos. La esencia del acto de insultar está en adjudicarle verbalmente al contrario algunos defectos, a menudo según el antojo del emisor; la verdad o la falsedad de las afirmaciones de éste son cuestiones que no se toman tanto en consideración ${ }^{26}$. Aunque, por otro lado, no se puede negar que la verosimilitud de que el destinatario tenga el defecto mencionado refuerza enormemente el poder del insulto, ya que lo que duele más es cuando aciertan en nuestro punto débil.

Conviene mencionar que no siempre durante el acto de insultar los defectos se atribuyen directamente al destinatario:

Los insultos [...] se ajustan para reproducir la realidad próxima a la cultura del hablante. [...] Eso se nota [...] dentro de España: en las zonas rurales, donde el entorno familiar y el honor forman parte de la vida cotidiana con más peso que en las urbanas, se insulta más mencionando a sus familiares que aludiendo al propio insultado (Diez, 2008).

A pesar de la existencia de numerosas culturas en nuestro planeta y, por tanto, diversos puntos de vista sobre lo que se considera como defecto, creemos que puede proponerse la siguiente división universal de los defectos que siempre quedan en el centro de interés del ser humano ${ }^{27}$ :

a) defectos físicos,

b) defectos psíquicos,

c) defectos relacionados con la vida en una sociedad (p.ej.: conducta moral, proveniencia social y cultural, profesión, religión).

La división presentada supra ha de ser, por razones obvias, muy general. Lo que algunos pueden considerar como defecto, otros pueden percibir como algo normal o extraordinario. Por supuesto, son otra vez las culturas que deciden y hay que ser conciente de que las preferencias cambian no sólo según el cambio del espacio, sino también según el paso del tiempo ${ }^{28}$.

${ }^{25}$ Otra forma de insultar es la de ordenar al destinatario hacer cosas repropadas moral y socialmente, o simplemente desagradables para éste, usando con este fin a menudo palabras vulgares, p.ej.: ;Vete a tomar por el culo! ¡Jódete! ;Lárgate! etc.

${ }^{26}$ Sobre todo que el emisor a menudo hace referencia a los defectos difícilmente comprobables o discutibles.

27 División elaborada, mayormente, según los resultados de las investigaciones de De Raad, Van Oudenhoven y Hofstede (2004) y Van Oudenhoven et al. (2008).

${ }^{28}$ El ejemplo muy conocido es el de las opulentas mujeres de Rubens, cuando la obesidad femenina en la época de barroco era vista como belleza. 


\subsection{UNIDADES LÉXICAS INSULTANTES}

Si hablamos de insultos en general, no cabe pensar solamente de los términos puramente insultantes. También en el campo de lo insultante hay que incluir toda una serie de palabras y expresiones que, en un determinado contexto, poseen una intención hiriente o degradante por parte del hablante.

Por 'léxico ofensivo' entendemos aquí tanto el considerado como insultante par excellence, como el léxico neutral. Se trata de las unidades léxicas de carácter ofensivo usadas con la intención de insultar.

La acción de insultar, tal como ya lo indicamos supra, pertenece al tipo de la agresión directa, que expresa de forma abierta la actitud negativa del emisor hacia el receptor del mensaje. La expresión de dicha actitud se manifiesta, entre otros recursos, a través del uso del léxico denigrante que, según Peisert (2004, p. 37), podemos dividir en dos grupos:

a) el léxico codificado, relativamente aceptable desde el punto de vista cultural (p.ej.: burro, inútil, fascista),

b) el léxico no-codificado, es decir, considerado como no aceptable en el uso "decente" de la lengua (p.ej.: joder, gilipollas, cagarse).

$\mathrm{Al}$ segundo de los grupos que se acaban de exponer pertenecen en gran parte las formas tabuizadas: palabras obscenas, indecentes, vulgares e inmorales. Por supuesto, la frontera entre estos dos grupos es borrosa y depende de muchos factores de carácter social y cultural.

Insultando, los hombres recurren al uso de una variedad de unidades léxicas que, desde el punto de vista lingüístico, pueden agruparse en diferentes áreas temáticas. Al igual que en el caso de los defectos, dichas áreas pueden variar en diferentes culturas; la variedad comprende no sólo el número de aquéllas, sino también su extensión. No obstante, consideramos posible elaborar una lista ${ }^{29}$, otra vez muy general, de las áreas temáticas más frecuentes dentro de las cuales se mueve la humanidad a la hora de insultar:

a) la naturaleza (en especial, el mundo de los animales),

b) sexualidad y partes íntimas del cuerpo humano,

c) actividades fisiológicas consideradas como desagradables ${ }^{30}$,

d) algunos aspectos relacionados con la vida en una sociedad ${ }^{31}$.

Como conviene sospechar, muchos conceptos de las áreas temáticas expuestas supra cuentan con más que un significante ${ }^{32}$. Ello puede ser explicado por varias cau-

${ }^{29}$ Elaborada, básicamente, según los resultados de las investigaciones de De Raad, Van Oudenhoven y Hofstede (2004) y Van Oudenhoven et al. (2008).

30 P.ej.: orinar, defecar, vomitar.

${ }^{31}$ P.ej.: profesión, nacionalidad, raza, religión, sexo, edad.

${ }^{32}$ Merece subrayar el papel del lenguaje coloquial en este aspecto. Esta variedad más utilizada de la lengua, entre cuyas características se encuentran la espontaneidad y la expresividad, trata de satisfacer las necesidades comunicativas diaras a nivel informal, siendo el insulto una de ellas. Es 
sas, entre ellas, la necesidad de poseer un buen caudal de voces ofensivas comparable con la tener un buen arma, o el desgaste pragmático de palabras, en este caso, insultantes.

Antes de cerrar el tema del léxico insultante, consideramos interesante mencionar la cuestión de la categoría gramatical en la expresividad de las palabras insultantes. Del trabajo de Van Oudenhoven et al. (2008, p. 175) se desprende que son los nombres $^{33}$ que parecen ser particularmente relevantes para insultar en la comunicación oral, en la que el lado pragmático se vuelve más importante. Según los autores, el uso de los nombres en el acto de insultar da la impresión de que el emisor quiere atribuir un rasgo más definitivo a la persona a la que se refiere (2008, p. 175). Así, de estos dos enunciados:

(a) "Eres idiota"

(b) "Eres un idiota" 34

el enunciado (b) es el que consolida más la opinión del emisor, confiriéndole de este modo un caráter más insultante. Esto ocurre porque: “...the nouns implies that the world puts people like this in a class by themselves" (Van Oudenhoven et al., 2008, p. 175).

\section{CONCLUSIONES}

El presente artículo se inscribe dentro de los estudios sobre la expresión emocional del signo lingüístico. El fenómeno del insulto constituye uno de los aspectos de estos estudios que, según nuestro conocimiento, ha sido poco analizado por la lingüística.

Conforme a la tesis en la que apoyamos nuestro trabajo, las voces insultantes son, sin duda, signos lingüísticos expresivos: participan en la expresión emocional, no en la descripción de las emociones. Si nos referimos a su calidad de los signos nominativos, dichas voces necesitan actualizarse en un enunciado concreto para cumplir con su doble papel:

a) expresar emoción (papel común para todos signos lingüísticos expresivos),

b) insultar al destinatario (papel exclusivo y primordial de las voces insultantes).

Aunque la actualización del valor insultante de las voces ofensivas se pone de manifiesto en un uso determinado de la lengua (en una situación concreta) y son los diferentes factores socio-culturales y pragmáticos que permiten descodificar la carga emocional que contienen, el mecanismo del acto de insultar es universal e igual para todas las culturas: humillar al destinatario atribuyéndole, habitualmente, defectos de varia índole.

dentro de la lengua coloquial donde nacen muchas voces denigrantes así que es inevitable que a menudo compartan el mismo significante.

33 Los autores utilizan el término "nombres referentes a la personalidad" (personality type nouns).

${ }^{34}$ Los ejemplos son nuestros. 
Según se desprende de los párrafos de nuestro artículo, el fenómeno del insulto es muy complejo, así que en un estudio profundizado de éste debería tomarse en cuenta:

- los participantes del acto de insultar,

- la perfectividad del acto (intención del emisor, impresión del destinatario),

- la especificidad de la cultura y la sociedad,

- tipo de los defectos que son pretexto para insultar,

- tipo del léxico ofensivo (codificado y no-codificado),

- áreas temáticas a las que pertenecen las palabras ofensivas,

- categoría gramatical de dichas palabras.

Todo eso demuestra que el estudio de los signos expresivos, nominales en este caso, debe apoyarse principalmente en la metodología de la pragmática lingüística y la de la lingüística cultural.

\section{BIBLIOGRAFÍA}

Bally, Ch. (1966). Definicja stylistyki. En R. Mayenowa, Stylistyka Bally'go. Wybór tekstów (pp. 39-74). Warszawa: Państwowe Wydawnictwo Naukowe.

Benveniste, É. (1966). Problèmes de linguistique générale. Paris: Éditions Gallimard.

Colín Rodea, M. (2005). Modelo interpretativo para el estudio del insulto. Estudios de Lingüistica Aplicada 041, 13-37.

Da Riva, R. (2007). Maledicta mesopotamica. Insultos e imprecaciones en el próximo oriente antiguo. Historiae, 4, 25-55.

De Raad, B., Van Oudenhoven, J.P., \& Merle, H. (2004). Personality Terms of Abuse in Three Cultures: Type Nouns between Description and Insult. European Journal of Personality, 4, 131-146.

Diez, J. (2008, agosto 3). El arte de insultar. Retrieved from http://www.elmundo.es/suplementos/ magazine/2008/662/1217414876.html

García de Diego, V. (1966). Lecciones de lingüística española. Madrid: Editorial Gredos, S.A.

Grabias, S. (1978). Pojęcie językowego znaku ekspresywnego. En K. Dejna (red), Z zagadnień słownictwa wspótczesnego języka polskiego (pp. 109-115). Wrocław: Ossolineum.

- (1981). O ekspresywności języka. Ekspresja a słowotwórstwo. Lublin: Wydawnictwo Lubelskie.

Grzegorczykowa, R. (1978). Struktura semantyczna wyrażeń ekspresywnych. En K. Dejna (red), Z zagadnień słownictwa wspótczesnego języka polskiego (pp. 117-123). Wrocław: Ossolineum.

- (1991). Obelga jako akt mowy. Poradnik Językowy, 5-6, 196-201.

Kövecses, Z. (2002). Metaphor and Emotion: Language, Culture and Body in Human Feeling. Cambridge: Cambridge University Press.

Mikołajczyk, B. (2007). Wyrażenia znieważające jako leksykalne środki realizacji aktów zagrażających twarzy na przykładzie języka niemieckiego i polskiego. En Kontakty językowe i kulturowe w Europie (p. 186-197). Gdańsk: Wydawnictwo Uniwersytetu Gdańskiego.

Nowakowska-Kempna, I. (1995). Konceptualizacja uczuć w języku polskim. Warszawa: Wyższa Szkoła Pedagogiczna Towarzystwa Wiedzy Powszechnej.

- (2000). Konstrukcje zdaniowe z leksykalnymi wykładnikami uczuć. Katowice: Uniwersytet Śląski. 
Peisert, M. (2004). Formy i funkcje agresji werbalnej. Próba typologii. Wrocław: Wydawnictwo Uniwersytetu Wrocławskiego.

Pisarkowa, K. (1978). Hasło "honor" jako przedmiot analizy pragmatycznojęzykowej. Polonica, IV, 117-135.

Spagińska-Pruszak, A. (1994). Język emocji. Studium leksykalno-semantyczne rzeczownika w języku polskim, rosyjskim i serbsko-chorwackim. Gdańsk: Wydawnictwo Uniwersytetu Gdańskiego.

Szumska, D. (2000). O emocjach bez emocji. Język a Kultura, 14, 199-208.

Van Oudenhoven, J. P., et al. (2008). Terms of abuse as expression and reinforcement of cultures. International Journal of Intercultural Relations, 32, 174-185.

Volek, B. (1987). Emotive signs in language and semantic functioning of derived nouns in Russian. Amsterdam - Philadelphia: John Benjamins Publishing Company. 